\title{
Impact of cyclosporine A use in the prevention of reperfusion injury in acute myocardial infarction: A meta-analysis
}

\author{
Sunil Upadhaya ${ }^{1}$, Seetharamprasad Madala ${ }^{1}$, Ramkaji Baniya ${ }^{1}$, \\ Suresh Kumar Subedi ${ }^{1}$, Kalyan Saginala ${ }^{2}$, Ghassan Bachuwa ${ }^{1}$ \\ ${ }^{1}$ Department of Internal Medicine, Hurley Medical Center/Michigan State University, \\ One Hurley Plaza, Flint, MI, United States \\ ${ }^{2}$ Department of Internal Medicine/Pediatrics, Hurley Medical Center/Michigan State University, \\ One Hurley Plaza, Flint, MI, United States
}

\begin{abstract}
Background: Reperfusion injury is an important limiting factor associated with revascularization in acute myocardial infarction (AMI). Various therapies have been tried in an attempt to prevent reperfusion injury, but the search has been elusive. The role of cyclosporine A (CsA) in the prevention of reperfusion injury in AMI is still not clear. The objective of this study was to find out whether CsA is beneficial in reducing reperfusion injury in acute ST elevation myocardial infarction.

Methods: We performed a systematic search of Pubmed, Scopus, clinicaltrial.gov, and Cochrane Database for randomized control trials (RCT) measuring the effect of CsA in AMI compared to a placebo. The Mantel-Haenszel method and random effect model were used to analyze the data. A total of 1,566 patients (776 in the CsA group and 790 in the placebo group), who participated in 5 RCTs were included in our meta-analysis.

Results: We did not find any significant differences between the CsA and placebo groups in terms of all-cause death (odds ratio [OR] 1.21, 95\% confidence interval [CI] 0.78-1.87) and cardiovascular death (OR 1.05, 95\% CI 0.66-2.49). Similarly, we did not find any significant differences in terms of cardiogenic shock, recurrent ischemia and myocardial infarction, heart failure and echocardiographic outcomes.
\end{abstract}

Conclusions: Cyclosporine A is not helpful in preventing reperfusion injury in AMI. (Cardiol J 2017; 24, 1: 43-50)

Key words: myocardial infarction, reperfusion injury, cyclosporine A, mitochondrial permeability transition pore protein

\section{Introduction}

Although we have seen substantial advancement in the field of coronary artery disease, mortality rates still remain high. Reperfusion injury is an additional insult to already ischemic myocardial tissue. While percutaneous coronary intervention (PCI) attenuates the ischemic injury, it inadvertently accentuates the reperfusion injury. The open- ing of the mitochondrial permeability transition pore (MPTP) is one of the important mechanisms leading to reperfusion injury and cardio-myocyte death [1]. Since 1980s, cyclosporine A (CsA) has been known to inhibit opening of the MPTP [2]. Several experimental animal studies have been conducted to find the effects of CsA in reperfusion injury [3-17] and a meta-analysis, which included experimental studies in animal models involving

Address for correspondence: Sunil Upadhaya, MD, Hurley Medical Center, 2 Hurley Plaza, ste 212, Flint, MI, 48503, USA, tel: 14694712579, 1810 262-7245, e-mail: supadha1@hurleymc.com

Received: 02.07.2016 Accepted: 19.09.2016 


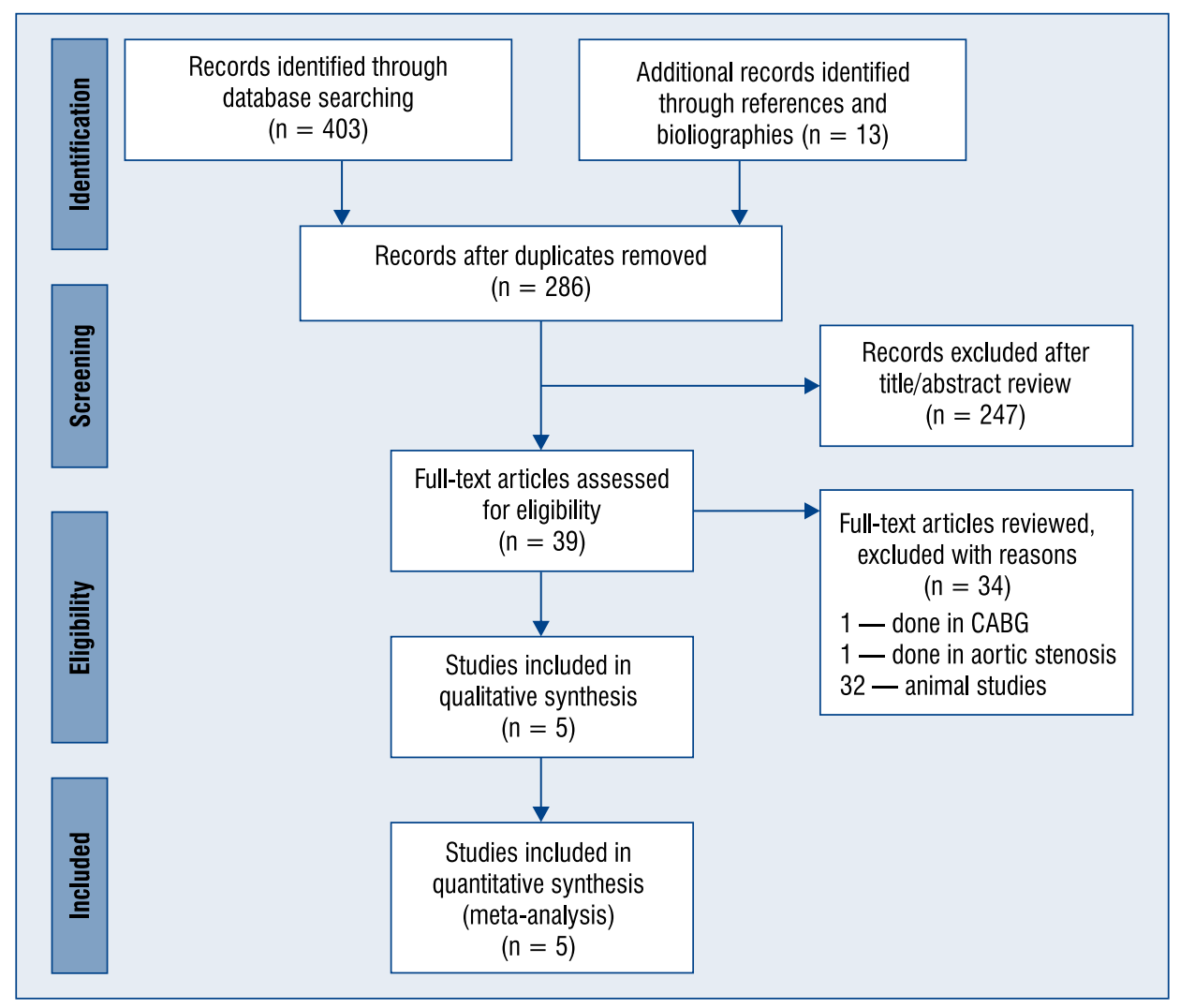

Figure 1. PRISMA diagram for the review; CABG — coronary artery bypass grafting.

CsA, showed reduced infarct size [18]. The first human study in acute ST elevation myocardial infarction (STEMI) using CsA was a small pilot study published in 2008 which showed reduced infarct size when compared to a placebo [19]. Studies published subsequently showed conflicting results [20]. We conducted this meta-analysis to find the protective effects of CsA in prevention of adverse clinical outcomes secondary to reperfusion injury.

\section{Methods}

The PRISMA statement for reporting metaanalyses and systemic reviews, as recommended by the Cochrane Collaboration, was used for this meta-analysis (Fig. 1) [21]. Our search for studies published by $30^{\text {th }}$ July 2016 , was conducted through Pubmed, Cochrane library databases, clinicaltrial. gov, and Scopus databases from inception. We used different strategies based on availability of Medical Subject Headings (MeSH) terms. For Pubmed and Cochrane library databases we used Mesh terms, "myocardial infarction" and "cyclosporine", connected with Boolean operator 'AND'. For Scopus and clinicaltrial.gov we used following Boolean search strategy: (Myocardial infarction OR MI OR ACS OR STEMI) AND (Cyclosporine OR Cyclosporins OR Cyclosporine A). Search strategies are elaborated on in Table 1. All results were reviewed. For our meta-analysis, we only used articles published in English. We took all measures necessary to prevent data duplication and used only published data. Publication bias was not measured due to the small number of studies analyzed.

The eligibility criteria for this meta-analysis stated that each study must: 1) include human subjects undergoing any intervention for STEMI, either percutaneous intervention or thrombolysis; 2) a randomized control trials (RCT) comparing pre-intervention CsA with a placebo; and 3) report relevant clinical or echocardiographic outcomes, whether primary or secondary. A total of $5 \mathrm{RCTs}$, which had been published in peer-reviewed journals, were included in our studies [19-24]. We extracted the baseline study details from all the selected trials (Tables 2, 3); outcomes not included in the analysis are listed in Table 4.

The clinical outcomes we measured were: all-cause death, cardiovascular death, heart fail- 
Table 1. Search strategies for different databases.

\begin{tabular}{ll}
\hline Databases & Search strategy \\
\hline Pubmed & (Cyclosporines [MeSH Terms]) AND (Myocardial infarction [MeSH Terms]) \\
SCOPUS & $\begin{array}{l}\text { TITLE-ABS-KEY (myocardial infarction OR ACS OR STEMI OR MI) AND TITLE-ABS-KEY } \\
\text { (Cyclosporine a OR Cyclosporine OR Cyclosporines) }\end{array}$ \\
Clinicaltrials.gov & $\begin{array}{l}\text { (myocardial infarction OR MI OR ACS OR STEMI) AND (Cyclosporine OR Cyclosporines OR } \\
\text { Cyclosporine a) } \\
\text { Cochrane library }\end{array}$ \\
\hline
\end{tabular}

Table 2. Baseline characteristics of the patients. Data are given in Cyclosporine group/Control group format.

\begin{tabular}{lccccc}
\hline & $\begin{array}{c}\text { Ottani et al. 2016, } \\
\text { CIRCUS study }\end{array}$ & $\begin{array}{c}\text { Cung et al. 2015, } \\
\text { CYCLE study }\end{array}$ & $\begin{array}{c}\text { Piot et al. } \\
\text { 2008 }\end{array}$ & $\begin{array}{c}\text { Ghaffari et al. } \\
\text { 2013 }\end{array}$ & $\begin{array}{c}\text { Mewton et al. } \\
2010\end{array}$ \\
\hline Number & $395 / 396$ & $207 / 203$ & $30 / 28$ & $50 / 51$ & $15 / 13$ \\
Age & $61.2 / 59.7$ & $62.5 / 63.2$ & $57 / 57$ & $64 / 60.3$ & $60 / 63$ \\
Male & $333 / 323$ & $167 / 160$ & $25 / 21$ & $38 / 46$ & $12 / 8$ \\
Body mass index & $26.6 / 26.9$ & $27.1 / 26.4$ & $26 / 27$ & N/A & $27 / 25$ \\
Smokers & $152 / 180$ & $84 / 81$ & $17 / 16$ & $16 / 19$ & $8 / 7$ \\
Diabetes mellitus & $54 / 48$ & $27 / 31$ & $4 / 4$ & $16 / 19$ & $4 / 3$ \\
Hypertension & $152 / 153$ & $114 / 113$ & $15 / 13$ & $21 / 22$ & $4 / 4$ \\
Dyslipidemia & $158 / 154$ & $72 / 83$ & $14 / 12$ & $8 / 6$ & $6 / 4$ \\
\hline
\end{tabular}

Table 3. In-hospital strategies. Data are given in Cyclosporine group/Control group format.

\begin{tabular}{|c|c|c|c|c|c|}
\hline & $\begin{array}{l}\text { Ottani et al. 2016, } \\
\text { CIRCUS study }\end{array}$ & $\begin{array}{l}\text { Cung et al. 2015, } \\
\text { CYCLE study }\end{array}$ & $\begin{array}{l}\text { Piot et al. } \\
2008\end{array}$ & $\begin{array}{c}\text { Ghaffari et al. } \\
2013\end{array}$ & $\begin{array}{c}\text { Mewton et al. } \\
2010\end{array}$ \\
\hline Aspirin & $371 / 363$ & $205 / 202$ & $29 / 24$ & $49 / 51$ & $15 / 13$ \\
\hline Heparin & $320 / 327$ & $175 / 171$ & $30 / 28$ & $48 / 51$ & $16 / 11$ \\
\hline GP IIb/IIla antagonist & $155 / 154$ & $90 / 92$ & $11 / 10$ & Not available & $4 / 5$ \\
\hline Beta-blocker & $424 / 455$ & $164 / 167$ & Not available & $46 / 45$ & $13 / 11$ \\
\hline ACEI/ARBs & $405 / 427$ & $147 / 146$ & Not available & $49 / 51$ & $13 / 10$ \\
\hline Anterior infarct & All anterior infarct & $102 / 101$ & $13 / 11$ & All anterior infarct & $7 / 5$ \\
\hline Primary intervention & $\mathrm{PCl}$ & $\mathrm{PCl}$ & $\mathrm{PCl}$ & Thrombolysis & $\mathrm{PCl}$ \\
\hline Initial TIMI flow < 2 & $345 / 361$ & $207 / 203$ & $3 / 1$ & Not applicable & $2 / 1$ \\
\hline $\begin{array}{l}\text { TIMI flow after PCI } \\
\text { or thrombolysis }\end{array}$ & $2.68 / 2.86$ & $2.82 / 2.88$ & $2.7 / 2.7$ & $2.63 / 2.78$ & $2.7 / 2.8$ \\
\hline Stent implanted & $323 / 338$ & 198/195 & $30 / 28$ & NA & $16 / 11$ \\
\hline
\end{tabular}

ACEI/ARBs - angiotensin converting enzyme inhibitor/angiotensin receptor blockers; GP — glycoprotein; $\mathrm{PCl}$ - percutaneous intervention; TIMI - Thrombolysis In Myocardial Infarction

ure, cardiogenic shock, recurrent ischemia and myocardial infarction, and major arrhythmias. We also measured echocardiographic outcomes: left ventricular ejection fraction (LVEF), left ventricular end-systolic volume and left ventricular end-diastolic volume. All of the outcomes were calculated with RevMan, version 5.3, for Win- dows (Cochrane Collaboration, Oxford, United Kingdom). Using random model, odds ratios (OR) were calculated with a confidence interval (CI) of $95 \%$ and heterogeneity was calculated with I2. Mean difference and random model were used to analyze continuous data. A p-value of $<0.5$ was considered significant. 
Table 4. Outcomes measured in the included studies, not measured in meta-analysis.

\begin{tabular}{|c|c|c|c|c|}
\hline & $\begin{array}{l}\text { Outcome }- \text { median (IQR) } \\
\text { or mean } \pm S D\end{array}$ & Cyclosporine & Control & $\mathbf{P}$ \\
\hline Cung et al., 2015 & ST segment resolution* & $52 \%$ & $49 \%$ & 0.55 \\
\hline \multirow[t]{3}{*}{ CIRCLE study } & High sensitivity cardiac TnT [ng/L] & $2160(1087-3274)$ & $2068(1117-3690)$ & 0.85 \\
\hline & LV wall motion score & $1.35 \pm 0.35$ & $1.34 \pm 0.34$ & 0.78 \\
\hline & LV akinetic/dyskinetic segments [\%] & $11.8 \pm 14.4$ & $12.6 \pm 14$ & 0.59 \\
\hline Ottani et al., 2016 & ST elevation post $\mathrm{PCl}[\mathrm{mm}]$ & $2.7 \pm 1.9$ & $2.7 \pm 1.9$ & NS \\
\hline \multirow[t]{2}{*}{ CIRCUS study } & Peak CK [IU/L] & $3992(1910-5447)$ & 3917 (1878-5608) & NS \\
\hline & Adverse LV remodeling $\ddagger$ & $42.8 \%$ & $40.7 \%$ & 0.53 \\
\hline \multirow[t]{3}{*}{ Piot et al., 2010} & $\begin{array}{l}\text { Area under curve CK release } \\
\text { [arbitrary unit] }\end{array}$ & $\begin{array}{c}138,053 \\
(114,008-283,461)\end{array}$ & $\begin{array}{c}247,930 \\
(145,639-404,349)\end{array}$ & 0.04 \\
\hline & $\begin{array}{l}\text { Area under curve } \mathrm{Tnl} \text { release } \\
\text { [arbitrary units] }\end{array}$ & $\begin{array}{c}112,312 \\
(48,680-153,956)\end{array}$ & $\begin{array}{c}129,320 \\
(65,019-224,116)\end{array}$ & 0.15 \\
\hline & $\begin{array}{l}\text { Mass of infarcted tissue } \\
\text { on MRI on day } 5[\mathrm{~g}]\end{array}$ & $37(21-51)$ & $46(20-65)$ & 0.04 \\
\hline $\begin{array}{l}\text { Mewton et al., } \\
2010\end{array}$ & Infarct size at 6 month [g] & $29 \pm 15$ & $38 \pm 14$ & 0.04 \\
\hline \multirow{3}{*}{$\begin{array}{l}\text { Ghaffari et al., } \\
2013\end{array}$} & Peak CK-MB [IU/L] & $271.8 \pm 210.1$ & $281.7 \pm 208.3$ & 0.81 \\
\hline & Peak-Tnl [ng/mL] & $17.7 \pm 11.2$ & $18.1 \pm 11.7$ & 0.86 \\
\hline & $\begin{array}{l}\% \text { ST segment resolution } \\
\text { at } 90 \text { min [min]† }\end{array}$ & $34.8 \pm 6.4$ & $36 \pm 11.2$ & 0.51 \\
\hline
\end{tabular}

${ }^{*} \geq 70 \%$ resolution of ST segment elevation at $1 \mathrm{~h}$ after $\mathrm{PCl}$.

$\ddagger$ An increase of $15 \%$ or more in the left ventricular end-diastolic volume.

tThe reduction of the highest ST-segment elevation in any lead by at least $50 \%$ of the initial value in the first $60-90$ min of treatment. CK-MB — creatine kinase MB fraction, IQR — interquartile range; LV — left ventricle; MRI — magnetic resonance imaging; NS — not significant; $\mathrm{PCl}$ - percutaneous coronary intervention; $\mathrm{SD}$ - standard deviation; $\mathrm{Tnl}$ - troponin I, TnT - troponin T

\section{Results}

A total of 1,566 patients were included in our analysis, with 776 in the group which received CsA and 790 in the placebo group. We found no significant differences between the two groups in terms of LVEF (mean difference 1.21, 95\% CI-0.65-3.07) and left ventricular end-systolic volume (mean difference 1.60, 95\% CI -4.01-7.22). Similarly, we did not find any significant differences in left ventricular end-diastolic volume (mean difference 3.32, 95\% CI -3.51-10.15) (Fig. 2). With regards to clinical outcomes, no significant differences in major arrhythmias (OR $0.84,95 \%$ CI $0.60-1.18$ ) or recurrent ischemia and myocardial infarction (OR $0.72,95 \%$ CI $0.34-1.53$ ) (Fig. 2) were found. Additionally, we did not find any significant differences when looking at all-cause death (OR 1.21, 95\% CI 0.78-1.87), cardiogenic shock (OR $1.23,95 \%$ CI 0.73-2.09), cardiovascular death (OR 1.05, 95\% CI $0.66-2.49$ ), and heart failure (OR $0.86,95 \%$ CI 0.55-1.35) (Fig. 3).

\section{Discussion}

The goal of our study was to find out whether the use of cyclosporine before reperfusion is associated with better clinical and echocardiographic outcomes or not. We did not find any significant differences between the two groups in terms of clinical and echocardiographic outcomes. The first proof-of-concept study of CsA (Sandimmune preparation) showed a significant difference in the release of creatine kinase when comparing the CsA group to the placebo group [19]. It was thought to bring paradigm shift in the prevention of reperfusion injury. Subsequently, a larger RCT (CIRCUS study) was done, however, it failed to show any benefits in terms of primary outcome (adverse left ventricular remodeling, all-cause mortality and hospitalization for heart failure) (OR 1.04, 95\% CI 0.78-1.39) [22]. As hypothesized by the authors, this was likely due to the use of a different formulation of CsA; the CIRCUS study used the CicloMulsion formulation instead of the Sandim- 


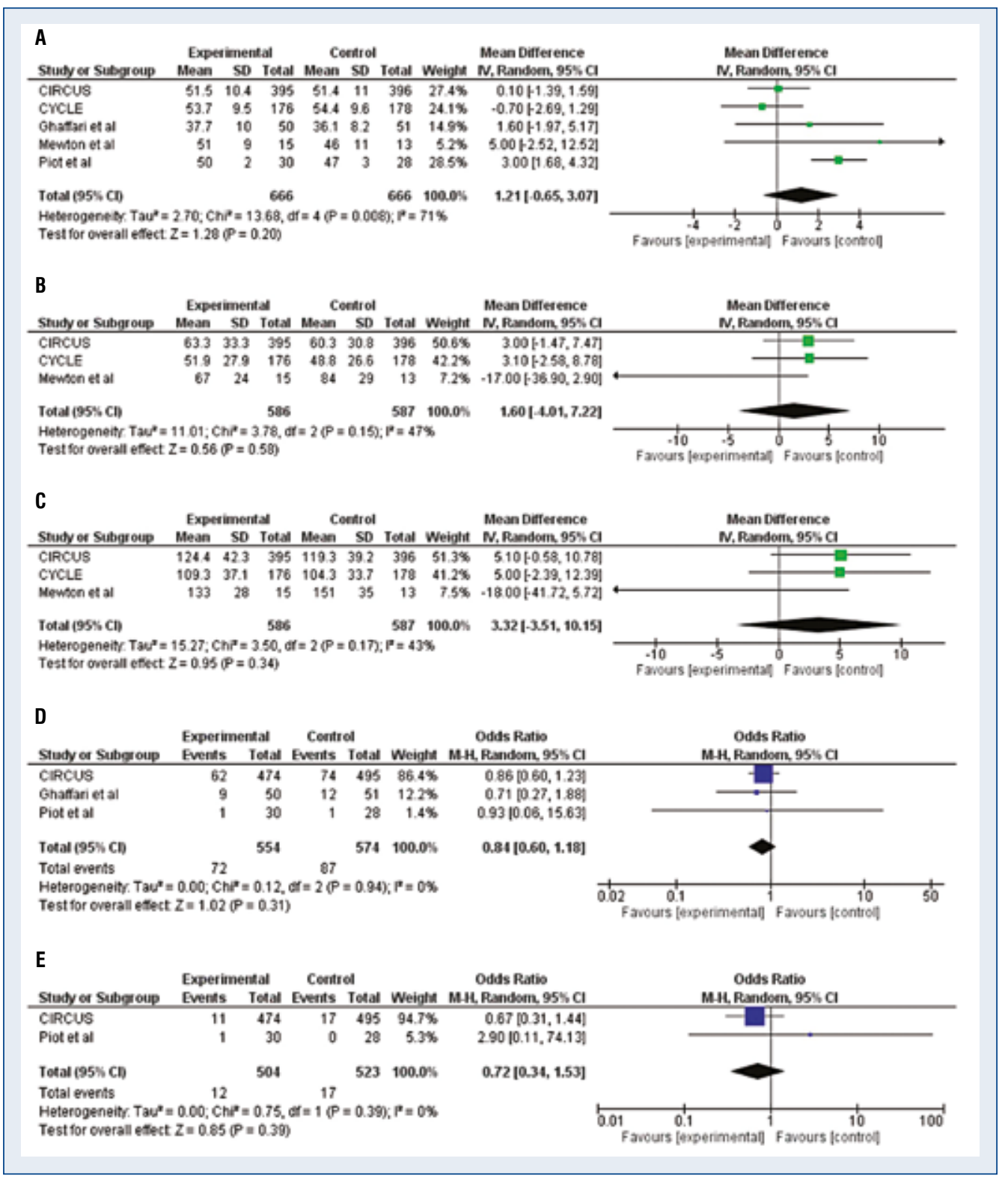

Figure 2. Forest plots of cyclosporine A versus placebo; A. Left ventricular ejection fraction; B. Left ventricular endsystolic volume; C. Left ventricular ejection diastolic volume; D. Major arrhythmia; E. Recurrent ischemia/myocardial infarction.

mune formulation. However, the recently published CYCLE study, which used the Sandimmune formulation, failed to show a significant difference in primary endpoint (resolution of ST-segment $\geq 70 \%$ ) [20]. The CicloMulsion preparation has been found to have similar pharmacokinetics and rather fewer adverse effects compared to Sandimmune preparation [25].

A study done on patients undergoing coronary artery bypass grafting surgery found no significant difference between the peak troponin T in CsA and placebo groups, except for the high-risk group with prolonged surgery - it showed that the extent of perioperative myocardial infarction was reduced in high-risk CsA patients [26]. Another RCT done in patients undergoing surgery for aortic stenosis showed a significant difference in the area under the curves for troponin I that favored the CsA group [27]. A few studies included in our meta-analysis used ST segment resolution as a surrogate marker of the successful coronary intervention [20,23]. It has been proven in multiple studies that early and complete ST segment resolution is associated with better outcomes [28]. 


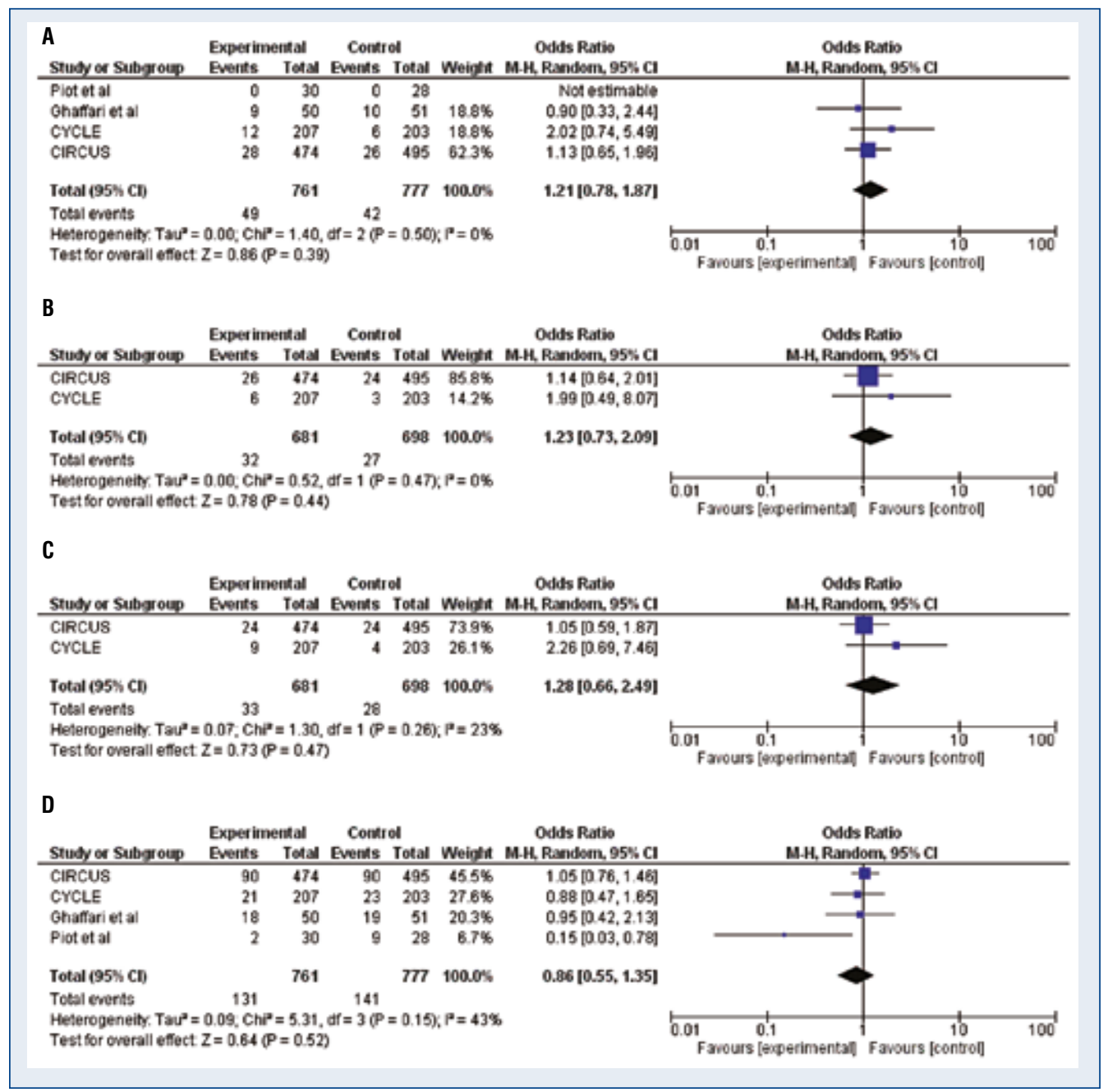

Figure 3. Forest plots of cyclosporine A versus placebo; A. All-cause death; B. Cardiogenic shock; C. Cardiovascular death; D. Heart failure.

Only the CYCLE study reported any adverse reactions to CsA. It reported a total of 5 adverse events, including one serious adverse drug reaction [20]. In all studies, CsA was given in a single injection just before the intervention. All human studies used a dose of $2.5 \mathrm{mg} / \mathrm{kg}$.

Several small pre-clinical studies have used CsA in animal models with mechanically occluded coronary arteries. There is extensive pre-clinical evidence that use of CsA during myocardial perfusion reduces myocardial infarct size by up to $50 \%$ $[29,30]$. This evidence not only regenerated the interest in reperfusion injury, but also leads to an increased understanding of the MPTP and Reperfusion Injury Salvage Kinase (RISK) pathway. In disagreement with animal studies, most of the clinical studies failed to show any benefit to using CsA in STEMI patients.
The failure of this translation is likely due in part to the poor methodology of the pre-clinical studies. No best practice standards exist for animal trials, which tend to lack statistical robustness. Most of the animal studies had a very small sample size. Furthermore, only a few studies calculated the sample size $[6,31]$ and most did not disclose conflicts of interests [18]. Additionally, while most of the studies were done in rodents [18], the majority of those done in pigs showed cyclosporine fail to decrease infarct size [3, 31]. This striking difference between two animal species indicates the existence of variation in the mechanism of reperfusion injury between species. This concern appears more compelling in light of evidence from experiments showing that pigs, unlike rodents, do not need RISK pathway activation for protection from reperfusion injury $[32,33]$. 
Another important root cause of failed translation is the inability of animal models to mimic the human pathology. Unlike animals, the human subjects in most trials had numerous comorbidities. The humans also were taking different medications which might interfere with reperfusion. Additionally, disease models in animal studies are created by mechanical occlusion of relatively healthy coronary arteries. Human subjects, however, have thrombus formation secondary to plaque rupture in atherosclerotic coronary arteries.

Finally, cyclosporine has unique pharmacodynamic and pharmacokinetic properties. Cyclosporine is mainly metabolized by cytochrome $\mathrm{P} 450$ 3A4 (CYP3A4). There are more than 20 genetic polymorphisms of the CYP3A4 gene [34]. Majority of these polymorphisms leads to decrease in function of the CYP3A4. Some of these polymorphisms are expressed by up to $9 \%$ of Caucasians [34]. Moving to pharmacokinetics, experiments have shown that CsA protects against reperfusion injury at a concentration between 0.4 and $2 \mu \mathrm{mol} / \mathrm{L}$ [35]. However, this protective effect is lost when the concentration exceeds $5 \mu \mathrm{mol} / \mathrm{L}$.

Several studies have shown $2.5 \mathrm{mg} / \mathrm{kg}$ to be the optimal dose for the best protection against reperfusion injury [36]. Contrary to this evidence, dose-dependent pro-apoptotic effects have been observed with cyclosporine in many pre-clinical studies [37]. With these considerations in mind, we believe that CsA-mediated protection is highly dose dependent and has a very narrow therapeutic index.

A recently published meta-analysis analyzed the effects of cyclosporine on the prevention of reperfusion injury in patients undergoing cardiac surgeries, PCI, and thrombolysis. It studied the effect on LVEF, creatine kinase-MB, and infarct size [38]. However, the authors did not report adverse events and mortality data. It included three of the RCTs included in our analysis, along with one RCT in patient undergoing coronary artery bypass surgery and one RCT in patient undergoing surgery for aortic stenosis [19, 23, 24, 26, 27]. Additionally, two of the larger trials comparing the effect of cyclosporine in acute myocardial infarction have been published recently and were not included in this study. This meta-analysis concluded that cyclosporine may not protect against reperfusion injury in clinical patients. The result of this metaanalysis is in concordance with our conclusion.

\section{Conclusions}

Cyclosporine A use prior to percutaneous intervention or thrombolysis failed to show any significant decrease in the clinical and echocardiographic outcomes in STEMI patients. It is time to explore new targets or other novel approaches to reduce reperfusion injury.

\section{Conflict of interest: None declared}

\section{References}

1. Ong S-B, Samangouei P, Kalkhoran SB, Hausenloy DJ. The mitochondrial permeability transition pore and its role in myocardial ischemia reperfusion injury. J Mol Cell Cardiol, 2015; 78: 23-34.

2. Crompton M, Ellinger H, Costi A. Inhibition by cyclosporin A of a $\mathrm{Ca} 2+$-dependent pore in heart mitochondria activated by inorganic phosphate and oxidative stress. Biochem J, 1988; 255: 357-360.

3. Karlsson LO, Zhou A-X, Larsson E et al. Cyclosporine does not reduce myocardial infarct size in a porcine ischemia-reperfusion model. J Cardiovasc Pharmacol Ther, 2010; 15: 182-189.

4. Boengler K, Hilfiker-Kleiner D, Heusch G, Schulz R. Inhibition of permeability transition pore opening by mitochondrial STAT3 and its role in myocardial ischemia/reperfusion. Basic Res Cardiol, 2010; 105: 771-785.

5. Matsubara M, Ranji M, Leshnower BG et al. In vivo fluorometric assessment of cyclosporine on mitochondrial function during myocardial ischemia and reperfusion. Ann Thorac Surg, 2010; 89: 1532-1537.

6. Dow J, Kloner RA. Postconditioning does not reduce myocardial infarct size in an in vivo regional ischemia rodent model. J Cardiovasc Pharmacol Ther, 2007; 12: 153-163.

7. Pagel PS, Krolikowski JG. Transient metabolic alkalosis during early reperfusion abolishes helium preconditioning against myocardial infarction: Restoration of cardioprotection by cyclosporin a in rabbits. Anesth Analg, 2009; 108: 1076-1082.

8. Gomez L, Paillard M, Thibault H, Derumeaux G, Ovize M. Inhibition of GSK3?? by postconditioning is required to prevent opening of the mitochondrial permeability transition pore during reperfusion. Circulation, 2008; 117: 2761-2768.

9. Fang J, Wu L, Chen L. Postconditioning attenuates cardiocyte ultrastructure injury and apoptosis by blocking mitochondrial permeability transition in rats. Acta Cardiol, 2008; 63: 377-387.

10. Leshnower BG, Kanemoto S, Matsubara M et al. Cyclosporine preserves mitochondrial morphology after myocardial ischemia/ reperfusion independent of calcineurin inhibition. Ann Thorac Surg, 2008; 86: 1286-1292.

11. Huhn R, Heinen A, Weber NC, Hollmann MW, Schlack W, Preckel B. Hyperglycaemia blocks sevoflurane-induced postconditioning in the rat heart in vivo: Cardioprotection can be restored by blocking the mitochondrial permeability transition pore. $\mathrm{Br}$ J Anaesth, 2008; 100: 465-471.

12. Lim SY, Davidson SM, Hausenloy DJ, Yellon DM. Preconditioning and postconditioning: The essential role of the mitochondrial permeability transition pore. Cardiovasc Res, 2007; 75: 530-535.

13. Xie J-R, Yu L-N. Cardioprotective effects of cyclosporine A in an in vivo model of myocardial ischemia and reperfusion. Acta Anaesthesiol Scand, 2007; 51: 909-913.

14. Ikeda Y, Miura T, Sakamoto J et al. Activation of ERK and suppression of calcineurin are interacting mechanisms of cardio- 
protection afforded by $\delta$-opioid receptor activation. Basic Res Cardiol, 2006; 101: 418-426.

15. Wang C, Neff DA, Krolikowski JG et al. The influence of B-cell lymphoma 2 protein, an antiapoptotic regulator of mitochondrial permeability transition, on isoflurane-induced and ischemic postconditioning in rabbits. Anesth Analg, 2006; 102: 1355-1360.

16. Krolikowski JG, Bienengraeber M, Weihrauch D, Warltier DC, Kersten JR, Pagel PS. Inhibition of mitochondrial permeability transition enhances isoflurane-induced cardioprotection during early reperfusion: The role of mitochondrial KATP channels. Anesth Analg, 2005; 101: 1590-1596.

17. Argaud L, Gateau-Roesch O, Chalabreysse L et al. Preconditioning delays $\mathrm{Ca} 2+$-induced mitochondrial permeability transition. Cardiovasc Res, 2004; 61: 115-122.

18. Lim WY, Messow CM, Berry C. Cyclosporin variably and inconsistently reduces infarct size in experimental models of reperfused myocardial infarction: A systematic review and metaanalysis. Br J Pharmacol, 2012; 165: 2034-2043.

19. Piot C, Croisille $\mathrm{P}$, Staat $\mathrm{P}$ et al. Effect of cyclosporine on reperfusion injury in acute myocardial infarction. N Engl J Med, 2008; 359: 473-481.

20. Ottani F, Latini R, Staszewsky L et al. Cyclosporine A in Reperfused Myocardial Infarction: The Multicenter, Controlled, Open-Label CYCLE Trial. J Am Coll Cardiol, 2016; 67: 365-374. Available from: http://www.ncbi.nlm.nih.gov/pub$\operatorname{med} / 26821623$

21. Beller EM, Glasziou PP, Altman DG et al. PRISMA for Abstracts: reporting systematic reviews in journal and conference abstracts. PLoS Med, 2013; 10: e1001419.

22. Cung T-T, Morel O, Cayla G et al. Cyclosporine before PCI in patients with acute myocardial infarction. N Engl J Med, 2015; 373: 1021-1031.

23. Ghaffari S, Kazemi B, Toluey M, Sepehrvand N. The Effect of prethrombolytic cyclosporine-a injection on clinical outcome of acute anterior ST-elevation myocardial infarction. Cardiovasc Ther, 2013; 31: 4 .

24. Mewton N, Croisille P, Gahide G et al. Effect of Cyclosporine on Left Ventricular Remodeling After Reperfused Myocardial Infarction. J Am Coll Cardiol, 2010; 55: 1200-1205.

25. Ehinger KHJ, Hansson MJ, Sjövall F, Elmér E. Bioequivalence and tolerability assessment of a novel intravenous ciclosporin lipid emulsion compared to branded ciclosporin in Cremophor ${ }^{\circledR}$ EL. Clin Drug Investig, 2013; 33: 25-34.
26. Hausenloy D, Kunst G, Boston-Griffiths E et al. The effect of cyclosporin-A on peri-operative myocardial injury in adult patients undergoing coronary artery bypass graft surgery: a randomised controlled clinical trial. Heart, 2014; 100: 544-549.

27. Chiari P, Angoulvant D, Mewton N et al. Cyclosporine protects the heart during aortic valve surgery. Anesthesiology, 2014; 121: 232-238.

28. Mauri F, Maggioni AP, Franzosi MG et al. A simple electrocardiographic predictor of the outcome of patients with acute myocardial infarction treated with a thrombolytic agent. A Gruppo Italiano per lo Studio della Sopravvivenza nell'Infarto Miocardico (GISSI-2)-Derived Analysis. J Am Coll Cardiol, 1994; 24: 600-607.

29. Hausenloy DJ, Maddock HL, Baxter GF, Yellon DM. Inhibiting mitochondrial permeability transition pore opening: A new paradigm for myocardial preconditioning? Cardiovasc Res, 2002; 55: 534-543.

30. Hausenloy DJ, Duchen MR, Yellon DM. Inhibiting mitochondrial permeability transition pore opening at reperfusion protects against ischaemia-reperfusion injury. Cardiovasc Res, 2003; 60: 617-625.

31. Lie RH, Stoettrup N, Sloth E, Hasenkam JM, Kroyer R, Nielsen TT. Post-conditioning with cyclosporine A fails to reduce the infarct size in an in vivo porcine model. Acta Anaesthesiol Scand, 2010; 54: 804-813.

32. Skyschally A, Van Caster P, Boengler K et al. Ischemic postconditioning in pigs: No causal role for risk activation. Circ Res, 2009; 104: 15-18.

33. Hausenloy DJ, Yellon DM. Reperfusion injury salvage kinase signalling: Taking a RISK for cardioprotection. Heart Fail Rev, 2007; $12: 217-234$

34. Lamba JK, Lin YS, Thummel $\mathrm{K}$ et al. Common allelic variants of cytochrome P4503A4 and their prevalence in different populations. Pharmacogenetics, 2002; 12: 121-132.

35. Nazareth W, Yafei N, Crompton M. Inhibition of anoxia-induced injury in heart myocytes by cyclosporin A. J Mol Cell Cardiol, 1991; 23: 1351-1354.

36. Huang K, Lu S-J, Zhong J-H, Xiang Q, Wang L, Wu M. Comparative analysis of different cyclosporine a doses on protection after myocardial ischemia/reperfusion injury in rat. Asian Pac J Trop Med, 2014; 7: 144-148.

37. Lotem J, Kama R, Sachs L. Suppression or induction of apoptosis by opposing pathways downstream from calcium-activated calcineurin. Proc Natl Acad Sci USA, 1999; 96: 12016-12020.

38. Song K, Wang S, Qi D. Effects of cyclosporine on reperfusion injury in patients: a meta-analysis of randomized controlled trials. Oxid Med Cell Longev, 2015; 2015. 